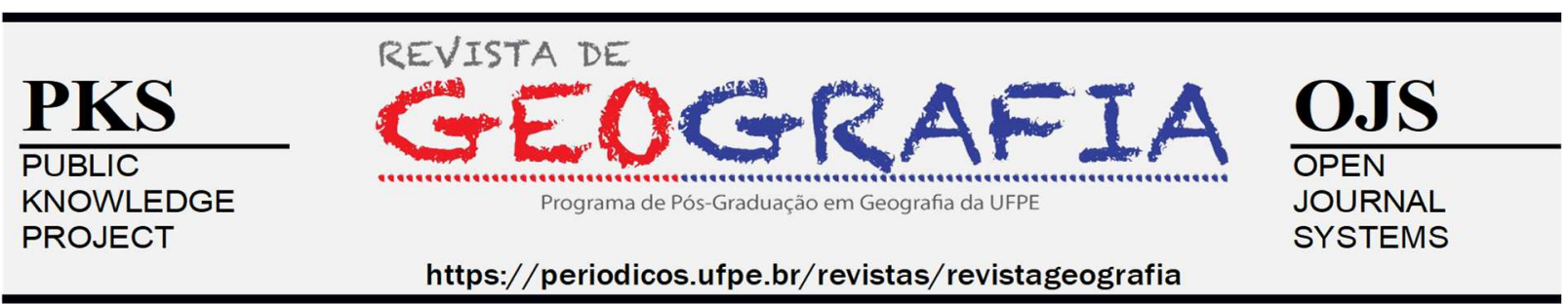

\title{
O USO DO MAPA DE KERNEL COMO SUBSÍDIO PARA IDENTIFICAÇÃO DA DISPERSÃO DOS FOCOS DE QUEIMADAS NO MUNICÍPIO DE MOSSORÓ (RN)
}

\author{
Luiz Tavernard de Souza Neto ${ }^{1}$, Maykon Targino da Silva ${ }^{2}$, Wesley Kevin Souto do Vale², \\ Alfredo Marcelo Grigio ${ }^{4}$
}

\begin{abstract}
${ }^{1}$ Bacharel em Gestçao Ambiental, Mestre em Ciências Naturais, Docente da Universidade do Estado do Rio Grande do Norte (UERN), luiztavernardsnt@ gmail.com, http://orcid.org/0000-0001-5543-4103

${ }^{2}$ Bacharel em Gestão Ambiental, Mestre em Ciências Naturais, Doutorando em Geologia na Universidade Federal do Ceará (UFC), maykontargino@ hotmail.com, http://orcid.org/0000-0002-9486-2714

3 Bacharel em Gestão Ambiental, colaborador do Núcleo de Estudos Socioambientais e Territoriais (NESAT/UERN), Universidade do Estado do Rio Grande do Norte (UERN), wesleysouto123@gmail.com, https://orcid.org/0000-0002-5080-3886

${ }^{4}$ Graduação em Geografia, Mestre e Doutor em Geodinâmica, Docente Adjunto II da Universidade do Estado do Rio Grande do Norte (UERN), alfredogrigio1970@ gmail.com, http://orcid.org/0000-0002-2094-9710
\end{abstract}

Artigo recebido em 25/07/2020 e aceito em 11/03/2021

\section{RESUMO}

Nas últimas décadas, é possível observar um crescente aumento no número de focos de queimadas no Brasil que acontece devido ao manejo inadequado do solo e pela falta de planejamento no uso e ocupação do território. Diante disso, o monitoramento de focos de queimadas, mediante sensoriamento remoto, é essencial para a compreensão do padrão espacial desses focos e no seu combate. Assim, o presente estudo objetivou identificar a dispersão dos focos de queimadas no município de Mossoró (RN). Como resultado, observou-se que em Mossoró (RN), no período compreendido entre os meses de agosto de 2015 e agosto de 2017, tiveram 540 focos de queimadas, e em sua maioria, com ocorrência na zona rural, sobretudo na região noroeste do município. Alguns focos também foram observados na zona urbana. Com os resultados foi possível observar uma relação entre a densidade de dispersão dos focos de queimadas e os fenômenos relacionados, sobretudo quando constatadas as práticas de manejo com a limpeza de terrenos para atividades agrícolas e loteamento para residências habitacionais que podem causar impactos ambientais significativos.

Palavras-chave: análise espacial; ações antrópicas; fenômenos espaciais; impactos ambientais significativos. 


\title{
THE USE OF THE KERNEL MAP AS A SUBSIDY FOR THE IDENTIFICATION OF THE DISPERSION OF FIRES OUTBREAKS IN THE MUNICIPALITY OF MOSSORÓ (RN)
}

\begin{abstract}
In recent decades, it is possible to observe an increasing number of outbreaks of fire in Brazil that occurs due to inadequate soil management and lack of planning in the use and occupation of the territory. Therefore, the monitoring fire foci, through remote sensing, is essential for understanding the spatial pattern of these focuses and in their combat. Thus, the present paper aimed to identify the dispersion of fire outbreaks in the municipality of Mossoró (RN). As a result, it was observed that in Mossoró (RN), in the period between August 2015 and August 2017, there were 540 outbreaks of fires, and mostly occurring in the rural area, especially in the northwest region of the municipality. Some outbreaks were also observed in the urban area. With the results, we observed a relationship between the dispersion density of the fire foci and the related phenomena, especially when we verified the management practices with the cleaning of land for agricultural activities and allotment for residencies that can cause significant environmental impacts.
\end{abstract}

Keywords: spatial analysis; anthropogenic actions; space phenomena; significant environmental impacts.

\section{EL USO DEL KERNEL MAP PARA LA IDENTIFICACIÓN DE LA PROPAGACIÓN DE LOS BROTES DE INCENDIOS EN EL MUNICIPIO DE MOSSORÓ (RN)}

\begin{abstract}
RESUMEN
En las últimas décadas fue posible observar un aumento en el número de brotes de incendios en Brasil que se produce debido a la gestión inadecuada de la tierra y la falta de planificación en el uso y ocupación del territorio. Por lo tanto, la vigilancia de los brotes de incendios, con el uso de la teledetección, es esencial para comprender el patrón espacial de estos focos y en su combate. Este estudio tuvo como objetivo el de identificar la dispersión de los brotes de incendios en el municipio de Mossoró (RN), Brasil. Como resultado se observó que en Mossoró (RN) entre agosto de 2015 y agosto de 2017 se produjeron 540 brotes de incendios y la mayoría se produjo en la zona rural, especialmente en la región noroeste del municipio. También se observaron algunos brotes en el área urbana. Con los resultados se pudo examinar una relación entre la densidad de propagación de los brotes de incendios y fenómenos relacionados, especialmente de las prácticas de manejo para actividades agrícolas y la subdivisión residencial de áreas que pueden causar impactos ambientales significativos.
\end{abstract}

Palabras clave: análisis especial; acciones antrópicas; fenómenos espaciales; impactos ambientales significativos. 


\section{INTRODUÇÃO}

Nas últimas décadas o número de focos de queimadas no Brasil vem aumentando consideravelmente. Isso se dá pelo manejo inadequado do solo e pela falta de planejamento no uso e ocupação do território. Na década de 70 o governo do Brasil incentivou a expansão da agropecuária, ao mesmo tempo esse aumento não foi acompanhado de um suporte técnico, e com isso, a técnica de queimadas, por exemplo, foi utilizada de forma deliberada para limpeza de terrenos como uma das medidas mais simples e de curto prazo (LIU, 2006).

De tal modo, com o passar do tempo a utilização sem planejamento da técnica de queimada vem gerando vários problemas. As queimadas em matas e em áreas de atividades agrícolas têm sido recorrentes e são considerados como uma das principais ameaças a manutenção da biodiversidade devido aos impactos ambientais. Ou seja, a perda de biodiversidade, a destruição dos microrganismos, o aumento do efeito estufa, a perda da fertilidade do solo, poluição do ar, tendo como efeito o aumento de casos de doenças respiratórias que são algumas das consequências decorrentes da prática de queimadas (GRENEMANN e CARNEIRO, 2009).

Nesse contexto insere-se o município de Mossoró (RN), localizado no estado do Rio Grande do Norte e pertencente ao semiárido nordestino do Brasil. O município tem uma posição de privilégio no cenário regional, sobretudo, por ser o segundo maior do Estado e por ter uma economia voltada para diversos setores de atividades, entre eles a atividade agrícola. Essa atividade no ano de 2015 ocupou uma área aproximada de $217,78 \mathrm{~km}^{2}$, o que equivale a $10,37 \%$ do território municipal, utilizada para lavouras permanentes e temporárias (IBGE, 2016).

É nesse cenário que surge a necessidade de identificar e monitorar as atividades antrópicas, principalmente, os focos de queimadas a fim de compreender e controlar as mesmas. Assim sendo, o uso de tecnologias que mensurem e monitorem os agentes causadores desses impactos vem se tornado cada vez mais essencial para os estudos ambientais, em especial a geoestatística e o geoprocessamento mediante o uso de produtos de sensoriamento remoto (SR).

Para pesquisas que empregam dados geoespaciais em seus campos de trabalho, a geoestatística pode ser utilizada como ferramenta para organizar variáveis qualitativas e quantitativas correlacionadas em suas semelhanças para gerar uma dispersão espacial com base nas características dos objetos ou fenômenos georreferenciados (MELO, 2016).

O geoprocessamento, neste caso, tem se utilizado da geoestatística para possibilitar a 
ampliação dos campos de estudo que utlizam dados geoespaciais para gerar produtos quantitativos e qualitativos para descrever a realidade em ambiente computadorizado. Por definição, o geoprocessamento pode ser entendido como um conjunto de técnicas matemáticas e computacionais que são utilizadas para tratamento e manipulação da geoinformação. Em seus processos, o geoprocessamento faz uso de uma série de tecnologias de coleta, armazenamento, tratamento, manipulação e consequentemente a apresentação das informações espaciais de um determinado objeto ou fenômeno com auxílio da Cartografia, Geodésia, Sistemas de Informações Geográficas (SIGs) e Sensoriamento Remoto (CÂMARA e MONTEIRO, 2001).

Dentro do conjunto de técnicas que o geoprocessamento faz uso, o sensoriamento remoto (SR) se define como uma tecnologia que objetiva à aquisição de dados da superfície terrestre ou de objetos específicos por meio de sensores que estão instalados em satélites (orbitais) ou plataformas terrestres ou aéreas. Os sensores produzem imagens por meio da captação da radiação eletromagnética refletida ou emidita de um objeto ou da superfície terrestre. (FLORENZANO, 2008)

Neste caso, as imagens de satélite obitidas por meio do SR surgem como um instrumento que pode auxiliar o planejamento ambiental, visto que, atualmente os satélites e radares fornecem informações de maneira satisfatória, auxiliando o monitoramento dos aspectos ambientais que impactam de forma significativa os sistemas ecológicos e a sociedade, tais como: queimadas (RODRIGUES et al., 2018), desmatamento (XIMENES et al., 2008), erosão (HIGA et al., 2014) e o uso e ocupação do solo (PRATES et al., 2017), dentre outros.

Para auxiliar o monitoramento de queimadas o Instituto Nacional de Pesquisas Espaciais (INPE) fornece por meio de um banco de dados, intitulado de Banco de Dados de Queimadas (BDQ), as coordenadas dos focos de calor acompanhadas da data e hora da ocorrência, bem como informações adicionais, a saber: se o dia choveu ou não, proximidade dos focos, sensor utilizado, etc. Informações essas, que podem ser disponibilizadas em uma tabela de atributos ou vetores em formato de pontos e estes armazenados em um arquivo com a extensão shapefile.

Do ponto de vista da pesquisa, o uso de métodos e técnicas que auxiliem na análise da espacialização dos fenômenos ambientais, como por exemplo, método de dispersão de Kernel, possibilita que dados desta natureza sejam empregados como base para realização de pesquisas voltadas para identificação de áreas impactadas e que sofreram ou que vem sofrendo com as 
ações antrópicas, sobretudo, na identificação de focos de queimadas. Diante do exposto, a presente pesquisa objetivou identificar a dispersão dos focos de queimadas no município de Mossoró no período compreendido entre 2015 e 2017.

\section{METODOLOGIA}

\section{Localização e caracterização da pesquisa}

O município de Mossoró está localizado (Figura 1) no Nordeste do Brasil, no Semiárido do Estado do Rio Grande do Norte e faz parte da Mesorregião do Oeste Potiguar. Situa-se a 290 km da capital, Natal e, seu acesso principal é pela Rodovia Federal pavimentada BR 304.

O município de Mossoró ( $\mathrm{RN}$ ) possui uma área territorial de 2.099,33 km² e uma população de 259.815 habitantes conforme Censo 2010. A densidade demográfica para o ano de 2010 foi de 123,76 hab/ $\mathrm{km}^{2}$, ultrapassando a média do estado do Rio Grande do Norte que consistiu em de 59,99 hab/ $\mathrm{km}^{2}$ (IBGE, 2010).

Figura 1 - Mapa de localização de Mossoró.

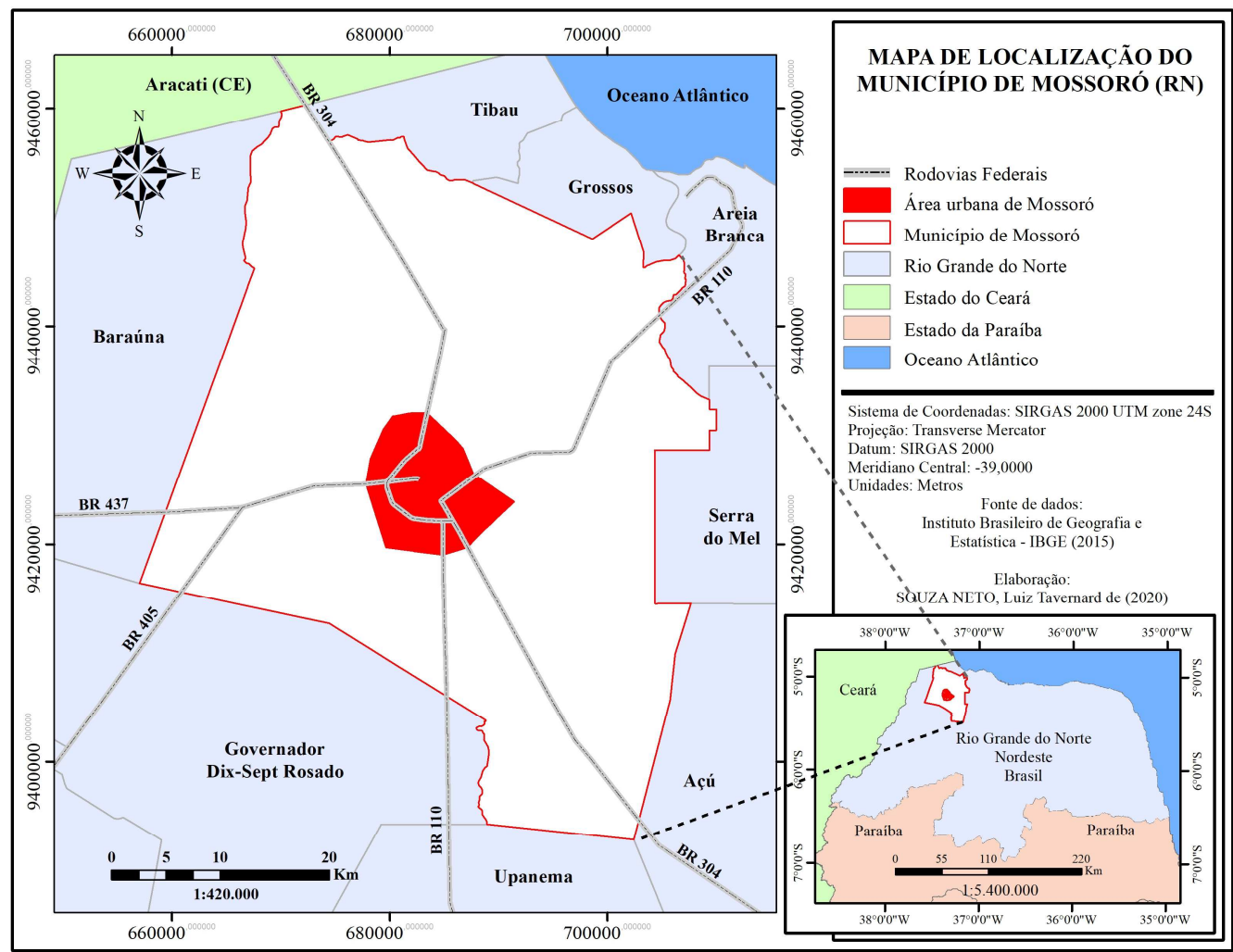

Souza Neto et al., 2021 
A população de Mossoró é predominantemente urbana, o que representa destacar que 237.241 habitantes $(91,31 \%)$ vivem em uma área aproximada de $113,80 \mathrm{~km}^{2}$, correspondendo apenas a 5,42\% do território total do município (IBGE, 2010). Na zona urbana a densidade demográfica para o ano de 2010 foi de $2.084,72$ hab $/ \mathrm{km}^{2}$. Na zona rural, o município apresenta uma área de 1.985,65 km², correspondente a 94,58\% de sua área total. A população rural chegou à marca de 22.574 habitantes $(8,69 \%)$ e densidade demográfica de 11,37 hab/km² (IBGE, 2010).

Mesmo tendo uma população predominantemente urbana, Mossoró em relação a sua área territorial, é hegemonicamente rural. Isso se reflete na grande variedade de atividades agrícolas e agropecuárias que se desenvolvem em várias porções do território municipal. Essa relação vem causando pressões significativas nos sistemas ambientais locais, por meio da utilização dos solos para práticas agrícolas e pastoril. Já na área urbana, os ambientais naturais estão dando espaço à implementação de loteamentos residenciais e expansão do perímetro urbano, o que tem ocasionado a supressão da vegetação nativa e a impermeabilização do solo.

Um dos segmentos mais importantes da atividade agrícola em Mossoró é a produção de frutas irrigadas com destaque para o melão e a banana, os quais apresentam uma participação significativa na balança comercial do estado, tornando o município um polo agrícola essencial para o desenvolvimento econômico da região (ANDRADE, 2015). Já as lavouras permanentes são: banana, castanha de caju, coco-da-baía, laranja, mamão, manga e maracujá. Todos produzidos em uma área destinada à colheita aproximada de $61,18 \mathrm{~km}^{2}$. Com relação as lavouras temporárias, para o ano de 2015, foi utilizada uma área plantada de $156,60 \mathrm{~km}^{2}$, com destaque: cebola, feijão, mandioca, melancia, melão, milho e sorgo (IBGE, 2016).

Em relação a condição climática, predomina para o município de Mossoró o clima semiárido, caracterizado por ser quente e com chuvas escassas e irregulares em boa parte do ano, com período chuvoso compreendido entre os meses de fevereiro a abril e precipitação pluviométrica média de $695,8 \mathrm{~mm} /$ ano e, temperatura média anual de 27,4 ${ }^{\circ} \mathrm{C}$. (CPRM, 2005).

Com relação aos recursos hídricos, Mossoró se encontra inserido na bacia hidrográfica do Rio Apodi-Mossoró com cursos de água com regimes intermitentes. Com relação as águas subterrâneas, o município encontra-se nos domínios hidrogeológicos do Grupo Barreiras (intersticial) e da Formação Jandaíra (cárstico-fissural) (CPRM, 2005).

Sobre essa condição climática, distingue-se em Mossoró o bioma Caatinga, marcado por oferecer um tipo de formação vegetal com propriedades bem definidas, caracterizado pela 
união de plantas do tipo xerófilas e hiperxerófilas que no geral são espinhosas de caráter mais seco e de porte baixo com folhagem decídua no período de estiagem. É possível identificar neste cenário a presença de carnaúbas em áreas mais úmidas, principalmente nas margens do rio Apodi-Mossoró e em suas zonas de drenagens. (CPRM, 2005; QUEIROZ, 2009).

\section{Universo e amostras da pesquisa}

Na aquisição dos dados, foi utilizado o Banco de Dados do Programa Queimadas do Instituto Nacional de Pesquisas Espaciais (INPE) como base para identificação da dispersão dos focos de queimadas no município de Mossoró (RN), com informações referentes aos anos de 2015 à 2017, divido em dois períodos: 16/08/2015 à 15/08/2016; e, 16/08/2016 à 16/08/2017 (Figura 2).

Figura 2 - Focos de queimadas para o município de Mossoró (RN) com base no período de análise: 16/08/2015 à 15/08/2016; e, 16/08/2016 à 16/08/2017.

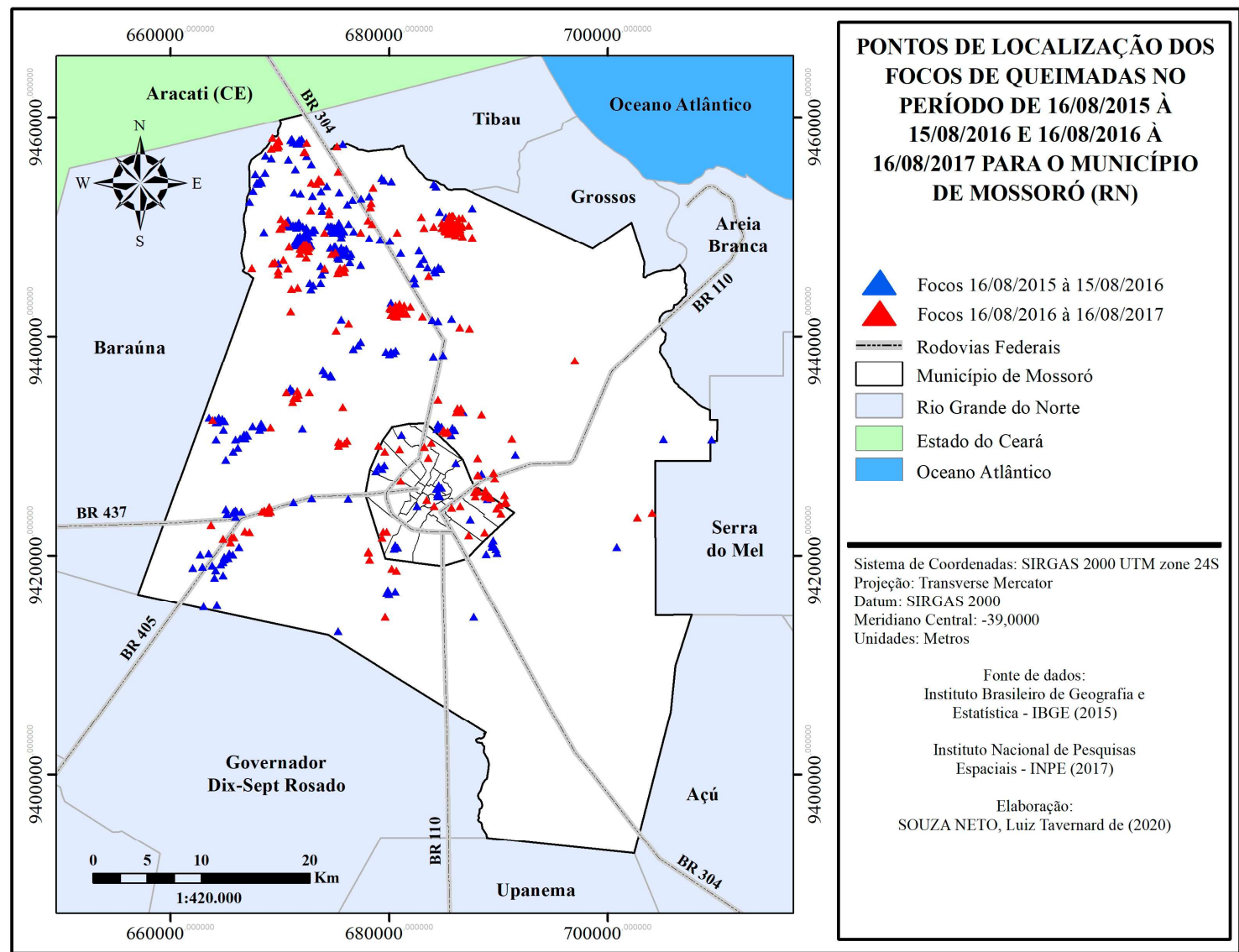

Souza Neto et al., 2021 
Na natureza, determinados fenômenos ocorrem no espaço e podem ser representados graficamente por meio de técnicas cartográficas (PARANHOS FILHO et al., 2016). Esses fenômenos georreferenciados podem ser transformados em uma informação geográfica - o dado geográfico - útil para análises em SIGs (MEIRELLES et al., 2007).

Essas análises que se dão mediante a espacialização de dados geoambientais, são potencializadas por técnicas geoestatísticas (YAMAMOTO e LANDIM, 2013) onde um exemplo é o trabalhado realizado por Melo et al. (2016) que avaliaram o grau de risco de eventos relacionados com os parâmetros precipitação e relevo na área urbana de Garanhuns $(\mathrm{PE})$.

Uma questão importante para esta pesquisa é o uso do conceito de queimada como base de observação pela impossibilidade de identificar os focos in loco e assim, não ter a informação se esses são indiscriminados, considerando que ocorrem de forma legal obedecendo a Legislação pertinente. E para a área urbana, utiliza-se o conceito de incêndio, ponderando que essa ação em aglomerados urbanos se torna ilegal perante a Legislação.

\section{Especificação dos modelos de análise e tratamento dos dados: produção dos mapas de Kernel}

As bases de dados para produção dos mapas da nossa pesquisa foram os focos apresentados na Figura 2. Para produção dos resultados, utilizou-se a técnica de elaboração dos mapas de Kernel (BEATO e ASSUNÇÃO, 2008). O estimador de densidade Kernel, é uma técnica de interpolação exploratória que gera uma superfície de densidade para a identificação visual chamadas de "áreas quentes" ou "hotspots". Compreende-se neste caso a ocorrência de uma área quente como uma concentração de eventos que indica de alguma forma a aglomeração de um fenômeno em uma distribuição espacial (SANT'ANA et al., 2014).

$\mathrm{Na}$ produção dos dados finais da pesquisa foi gerada uma nuvem de pontos contendo informações por ano dos focos de queimadas cometidas no município de Mossoró. Estes foram a base para geração dos mapas de densidade. Para isto, fez-se uso do estimador de densidade kernel, contido na ferramenta Mapa de Calor do QGIS Desktop 3.0.3 (QGIS Development Team, 2018), por meio da ferramenta "Mapa de calor (Estimativa de densidade Kernel)" (Figura 3). A partir da função Mapa de calor, obte-se um arquivo matricial como resultado da 
soma do empilhamento de " $n$ " outros raster circulares de raio "h" para cada ponto do dado de entrada segundo a fórmula (1) abaixo:

$$
\hat{f}_{h}(x)=\frac{1}{n h} \sum_{i=1}^{n} K\left(\frac{x-X_{i}}{h}\right)
$$

De acordo com Oliveira e Oliveria (2017), a fórmula acima tem a seguinte descrição:

- $\mathrm{K}$ = função de kernel

- $\mathrm{h}=$ raio de busca

- $\mathrm{x}=$ posição do centro de cada célula do raster de saída

- $\mathrm{Xi}=$ posição do ponto i proveniente do centroide de cada polígono

- $\mathrm{n}=$ número total de focos de calor

Figura 3 - Ferramenta "Mapa de calor (Estimativa de densidade Kernel)" do Software QGis Desktop 3.0.3.
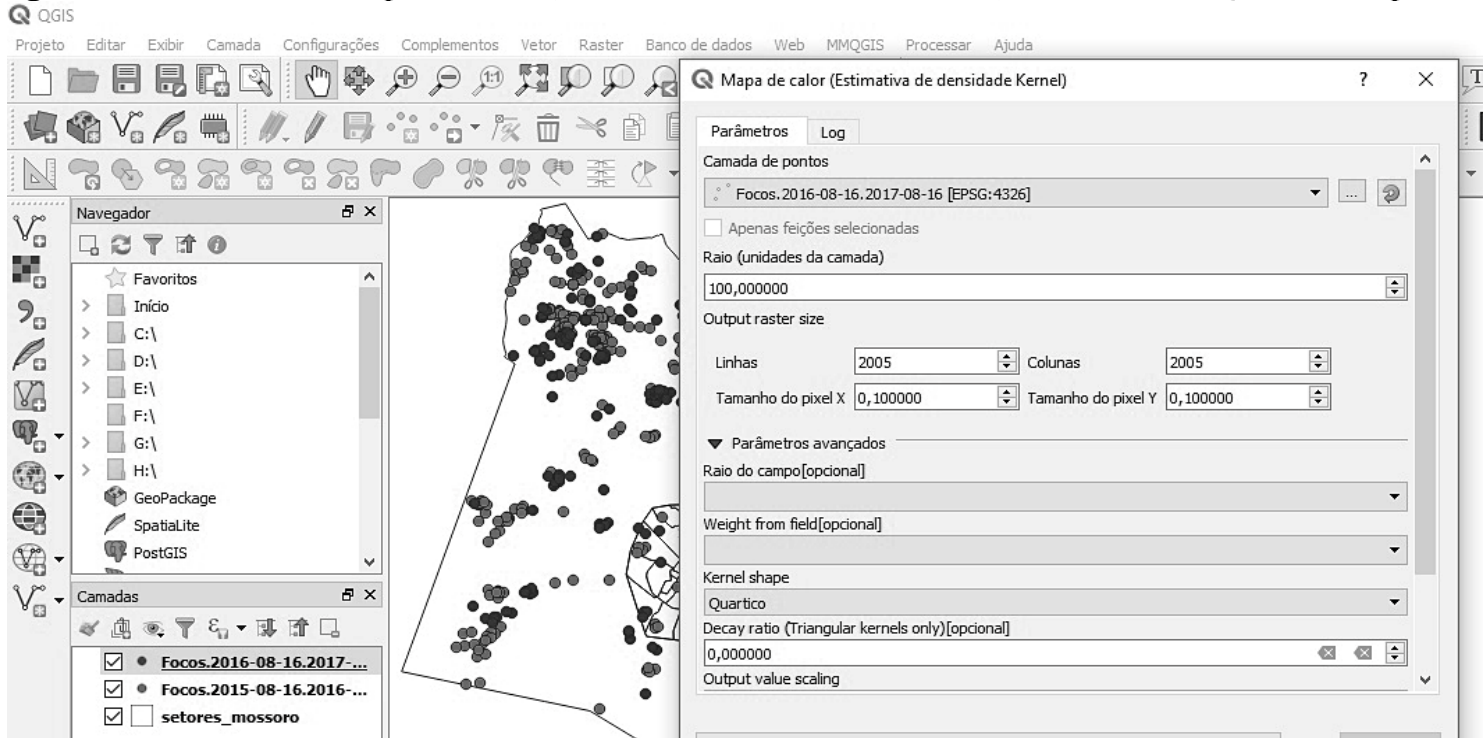

Como chave de interpretação das imagens do estimador de densidade Kernel, utilizouse a tonalidade/cor (para interpretação dos hotspots) e localização conforme Florenzano (2008). Com relação a tonalidade/cor, buscou-se demonstrar uma composição de cores (color ramp), para proporcionar a análise das imagens com base em um gradiente, como amostras, a cor branca (R255 G255 B255) representativa para as áreas sem incidência de focos de queimadas, a cor cinza (R240 G240 B240) para áreas com baixa incidência de focos e a cor vermelha (R232 
G21 B21) para áreas com alta incidência de focos de queimadas. A interpretação com base na localização se apresenta como condição para que sejam identificados os focos conforme a distribuição no território municipal, neste caso, zona rural, zona urbana e assentamentos rurais.

A interpretação da imagem por meio de "chaves" possibilita que o pesquisador possa compreender a dinâmica territorial ou a disposição de objetos com base em um conjunto de elementos de interpretação dando significado ao que é visível e o que não diretamente observado na imagem (FLORENZANO, 2008).

\section{RESULTADOS E DISCUSSÃO}

Mesmo sendo permitida em algumas situações, as queimadas têm um grande potencial de causar impactos negativos a biodiversidade e a qualidade de vida das comunidades humanas (GONÇALVES et al., 2009; NASCIMENTO e DE MEDEIROS, 2012) que estão nas áreas de influência direta e indireta dessas atividades. No entanto, os impactos tornam-se mais evidentes em ambientes que apresentam particularidades que facilitam esse processo de degradação, como por exemplo, o semiárido brasileiro, caracterizado por possuir um clima quente e seco, com baixa pluviosidade e irregularidade na distribuição das chuvas ao logo do ano.

Tais condições, se remetem ao território do município de Mossoró, onde a atividade rural e urbana tem se consolidado na exploração e produção agrícola e na expansão de sua área urbana com surgimento de novos loteamentos residenciais. Assim, os motivos para o surgimento de queimadas, são vários, entre eles: limpeza para colheitas e formação de pastos em áreas rurais e, os incêndios em áreas urbanas decorrentes dos desmatamentos da vegetação nativa para a construção de loteamentos e destinação final de resíduos sólidos domiciliares e industriais.

$\mathrm{Na}$ tabela 1, observa-se a distribuição por meses dos focos de queimadas para o município de Mossoró no período que compreende os anos de 2015 a 2017 com base no Programa Queimadas do Instituto Nacional de Pesquisas Espaciais (INPE). 
Tabela 1 - Quantitativo dos focos de queimadas para Mossoró entre os anos de 2015 e 2017.

\begin{tabular}{|c|c|c|c|c|c|c|c|c|c|c|c|c|c|c|}
\hline \multicolumn{15}{|c|}{ Período em meses } \\
\hline Período 1 & $\begin{array}{l}\text { Ago }^{1} \\
2015\end{array}$ & $\begin{array}{c}\text { Set } \\
2015\end{array}$ & $\begin{array}{r}\text { Out } \\
2015\end{array}$ & $\begin{array}{l}\text { Nov } \\
2015\end{array}$ & $\begin{array}{c}\text { Dez } \\
2015\end{array}$ & $\begin{array}{c}\text { Jan } \\
2016\end{array}$ & $\begin{array}{c}\text { Fev } \\
2016\end{array}$ & $\begin{array}{l}\text { Mar } \\
2016\end{array}$ & $\begin{array}{c}\mathrm{Abr} \\
2016\end{array}$ & $\begin{array}{l}\text { Mai } \\
2016\end{array}$ & $\underset{2016}{\operatorname{Jun}}$ & $\underset{2016}{\text { Jul }}$ & $\begin{array}{l}\mathrm{Ago}^{2} \\
2016\end{array}$ & Total \\
\hline $\begin{array}{c}16 / 08 / 2015 \\
- \\
15 / 08 / 2016\end{array}$ & 20 & 50 & 63 & 31 & 8 & 4 & - & - & 3 & 9 & 45 & 45 & 14 & 292 \\
\hline Período 2 & $\begin{array}{l}\text { Ago }^{3} \\
2016\end{array}$ & $\begin{array}{c}\text { Set } \\
2016\end{array}$ & $\begin{array}{c}\text { Out } \\
2016\end{array}$ & $\begin{array}{r}\text { Noy } \\
2016 \\
\end{array}$ & $\begin{array}{c}\text { Dez } \\
2016 \\
\end{array}$ & $\begin{array}{c}\text { Jan } \\
2017 \\
\end{array}$ & $\begin{array}{c}\text { Fev } \\
2017 \\
\end{array}$ & $\begin{array}{l}\text { Mar } \\
2017 \\
\end{array}$ & $\begin{array}{r}\mathrm{Abr} \\
2017\end{array}$ & $\begin{array}{l}\text { Mai } \\
\mathbf{2 0 1 7} \\
\end{array}$ & $\underset{2017}{\text { Jun }}$ & $\underset{2017}{\text { Jul }}$ & $\begin{array}{l}\text { Ago }^{4} \\
2017 \\
\end{array}$ & Total \\
\hline $\begin{array}{c}16 / 08 / 2016 \\
- \\
16 / 08 / 2017\end{array}$ & 9 & 63 & 19 & 87 & 30 & 10 & 4 & - & 1 & 12 & 1 & - & 11 & 248 \\
\hline
\end{tabular}

Fonte: adaptado de INPE (2017)

${ }^{1}$ Período de 16.08 à 30.08.15; ${ }^{2}$ Período de 03.08 à $14.08 .16 ;{ }^{3}$ Período de 18.08 à $31.08 .16 ;{ }^{4}$ Período de 03.08 à 15.08.17.

Destaca-se como observado na tabela 1, o registro de 540 focos de queimadas, onde no período compreendido entre 16/08/2015 e 15/08/2016 ocorreu o maior número de focos (292). Outra informação importante contida nos dados é que no Período 1, é o momento episódico dos focos, sendo que 98,97\% (289 focos) foram observados em períodos de estiagem, a estação chuvosa em Mossoró ocorre normalmente entre os meses de fevereiro e abril (CPRM, 2005). Com relação ao Período 2 compreendido entre 16/08/2016 e 16/08/2017, observa-se que $87,90 \%$ dos focos incidiram entre os meses de agosto de 2016 e janeiro de 2017. O total acumulado de focos atingiu a marca de 217 ocorrências.

De tal modo, os meses que apresentam maiores índices de focos de queimadas em Mossoró, são os meses que coincidem com o período de estiagem, fato este também ressaltado no Estado da Paraíba (VILAR e SILVA, 2016) e de Alagoas (FERNANDES e CARVALHO, 2014). Tal condição pode potencializar o aumento das queimadas e consequentemente na piora da qualidade do ar dessas áreas com maior incidência de focos.

Entre os meses de agosto e dezembro de 2015 só foi registrado $1 \mathrm{~mm}$ de chuva para o município de Mossoró. Neste mesmo período, foram observados 172 focos de queimadas. Já entre os meses de agosto e dezembro de 2016 foram registrados somente 3,6 $\mathrm{mm}$ de precipitação, enquanto isso, tiveram ocorrência de 216 focos (INPE, 2017; EMPARN, 2017). Esses são dados que demonstram uma disposição maior da região, no surgimento de focos de queimadas em períodos de estiagem corroborando, assim, com o que foi observado na literatura (FERNANDES e CARVALHO, 2014; VILAR e SILVA, 2016).

Assim sendo, com base nos dados da tabela 1, foi possível a organização dos focos de queimadas por meio do mapa de Kernel (Figura 4), o que permitiu a identificação dos padrões 
de dispersão desses focos no território mossoroense. Na figura 4, percebe-se um padrão de alta quantidade de focos de queimadas na porção Noroeste do município de Mossoró, com 96 ocorrências entre os meses de setembro de 2015 e julho de 2016, sendo esses dois meses, respectivamente, os que tiveram maiores ocorrências, 21 e 63, respectivamente.

Esta é uma área de extensa atividade agrícola, onde situam-se também alguns assentamentos rurais do Instituto Nacional de Colonização e Reforma Agrária (INCRA), entre eles: os assentamentos Maísa e Olga Benário. Já nas áreas 2 e 3 apontadas no mapa (figura 4), foi identificada uma menor intensidade de focos, porém se somados, atingem uma marca de 50 ocorrências.

Figura 4 - Mapa de dispersão dos focos de queimadas observados no Período 1 (16/08/2015 a 15/08/2016).

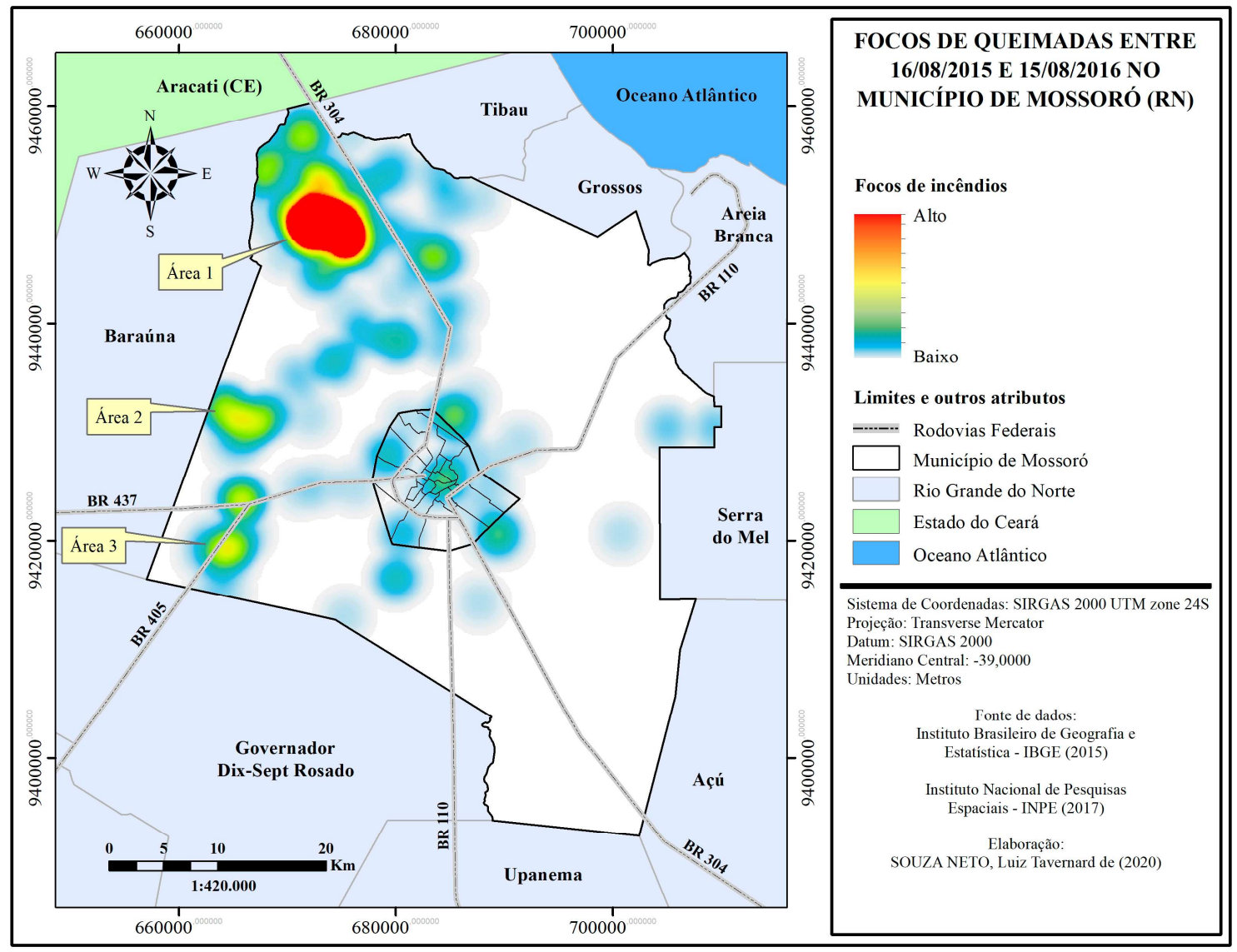

$\mathrm{Na}$ Área 1, localizada na figura 4, no foco ocorrido nas coordenadas UTM Zona $24 \mathrm{~S}$ 667533 E / 9453114 (Figura 5) é apresentada a sequência cronológica de acontecimentos que corroboram com a prática de limpeza da área para fins agrícolas, utilizando a técnica de queimadas controladas com uso de empilhamentos. 
Na técnica empregada para queimadas controladas, "o material a ser queimado é empilhamento em montes ou leiras. Esse material, chamado de combustível pode ser pesado (como troncos, galhos, etc.) ou leves (como plantas secas, capim, etc.)" (ASSOCIAÇÃO CAATINGA, 2011, p. 15).

Figura 5. Sequência de fatos ocorridos antes e depois do foco localizado nas coordenadas UTM Zona $24 \mathrm{~S}$ 667533 E / 9453114 N (SIRGAS 2000): A. 25/02/2014; B. 14/07/2016; C. 25/08/2016; D. 15/02/2017.
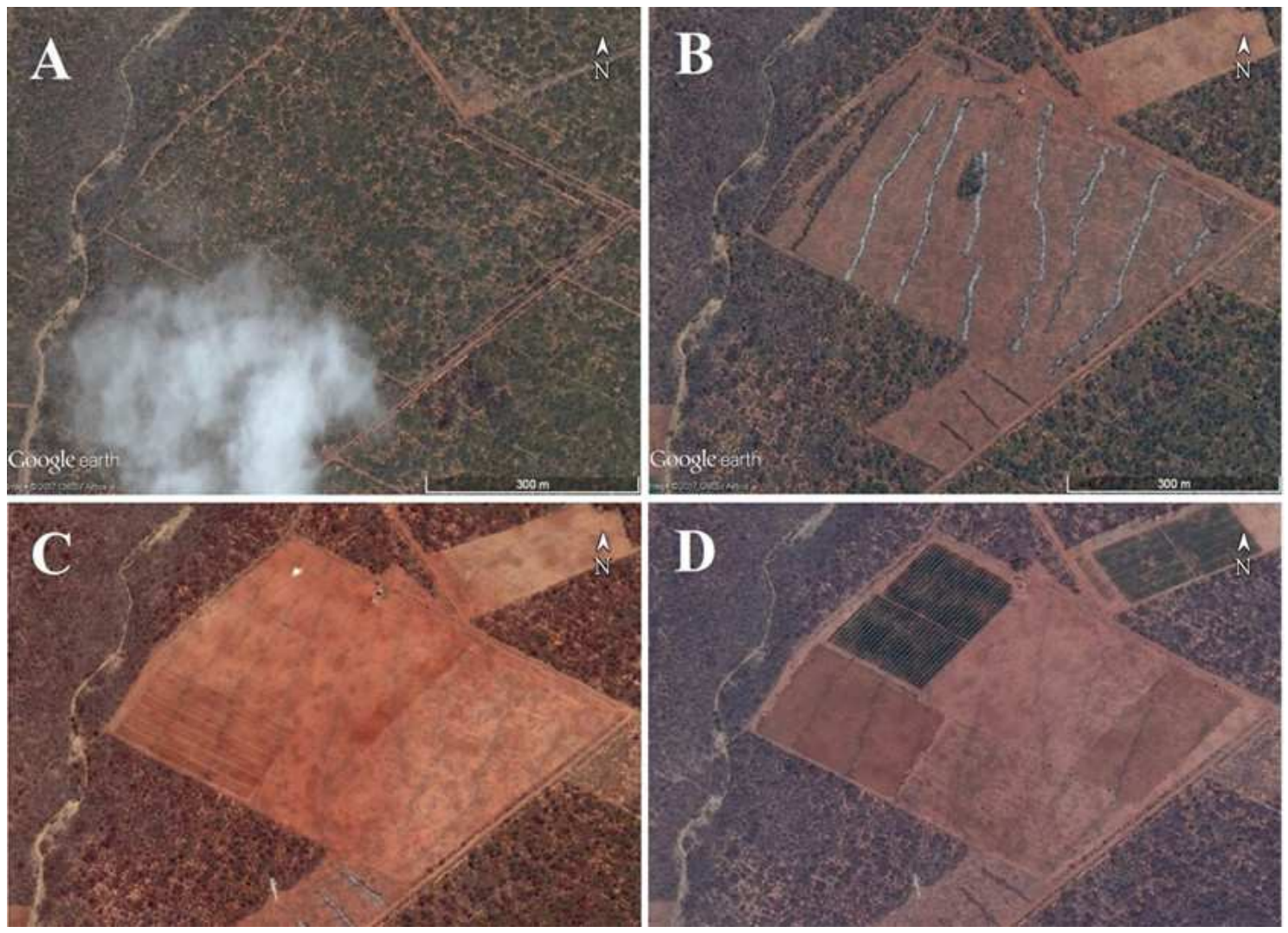

Fonte: Adaptado de Google Earth Pro (2015).

A figura 5B foi lançada um dia após ao foco observado nos dados do Programa Queimadas, ou seja, o foco foi registrado no dia 13 de julho de 2016 e a imagem é datada do dia 14 do mesmo mês e ano. É importante destacar que a figura 5A apresenta a área antes da limpeza do terreno e na 5B, e neste caso notamos a formação de montes ou leiras. Já a figura 5C representa a área já limpa após o manejo. Na figura 5D é possível constatar práticas agrícolas sendo desenvolvidas no local.

Os dados e a figura 4 ainda apontaram a ocorrência de 5 focos de incêndios no dia 19 de outubro de 2016 no perímetro urbano (bairros Centro e Ilha de Santa Luzia). Estes focos 
podem ser notados pelos registros fotográficos feitos em 2015 (Figura 6).

Figura 6 - Registros fotográficos dos focos de incêndios ocorridos no dia 19 de outubro de 2015 no perímetro urbano do município de Mossoró (RN) localizado nas coordenadas UTM Zona 24 S 684446 E / 9425435 N (SIRGAS 2000): A. Local de ocorrência do foco de incêndio; B. Bombeiros trabalhando no controle do incêndio.
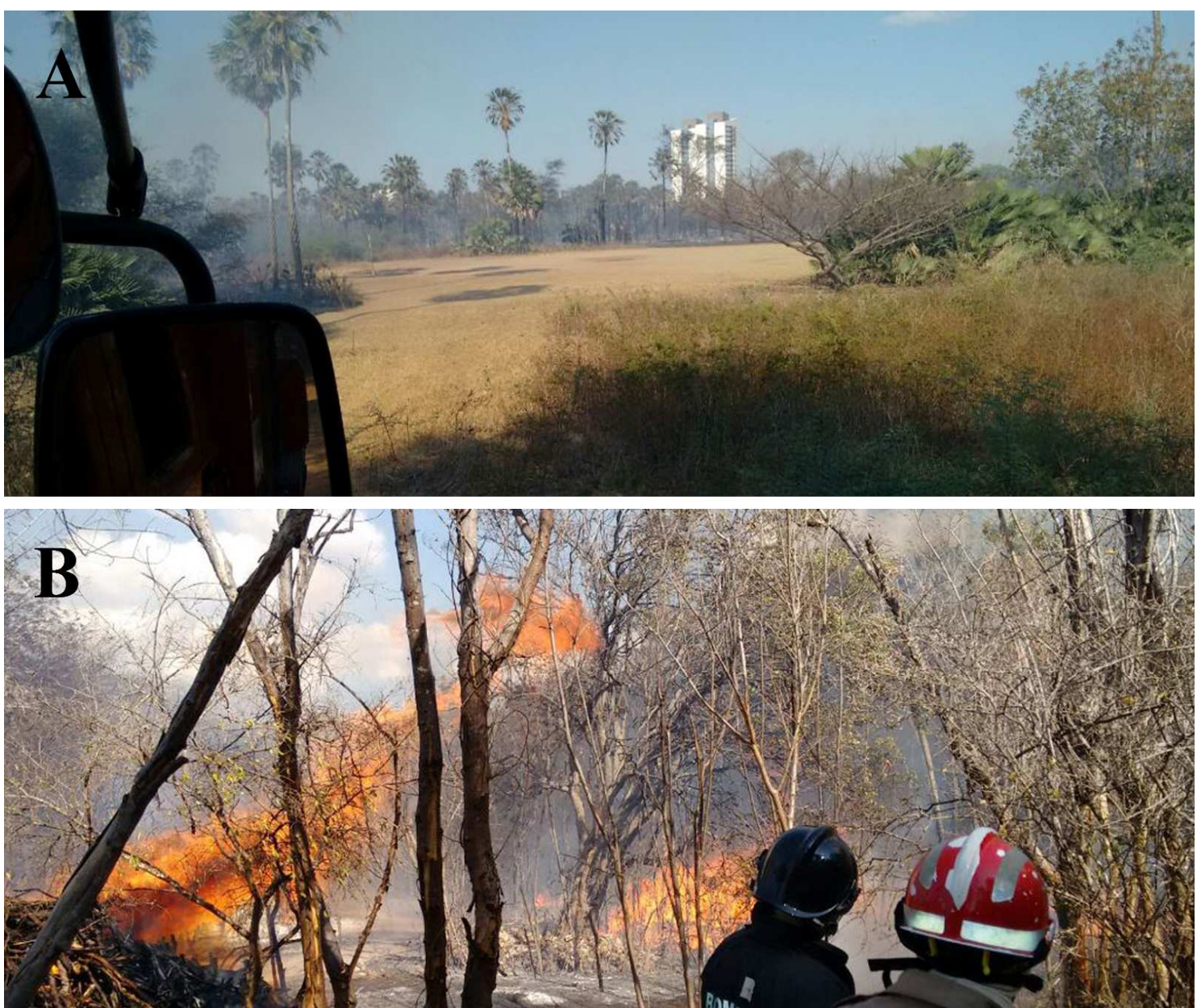

Fonte: Adaptado do Sítio eletrônico 4DZ Patrulha - http://www.4dzpatrulha.com/2015/10/bombeiros-controlaincendio-no-sitio.html.

Em relação ao Período 2, compreendido entre 16/08/2016 e 16/08/2017 (Figura 7), os focos apresentam um padrão de dispersão mais intenso na porção mais ao norte do município de Mossoró, porém notamos mais três áreas que se destacam, entre elas uma área mais central, localizada no perímetro urbano, nas proximidades do Horto Florestal da sede do Instituto Brasileiro do Meio Ambiente e dos Recursos Naturais Renováveis (IBAMA) e do Parque Municipal de Mossoró Maurício de Oliveira - parque urbano. 
Figura 7 - Mapa de dispersão dos focos de queimadas observados no Período 2 (16/08/2016 a 16/08/2017).

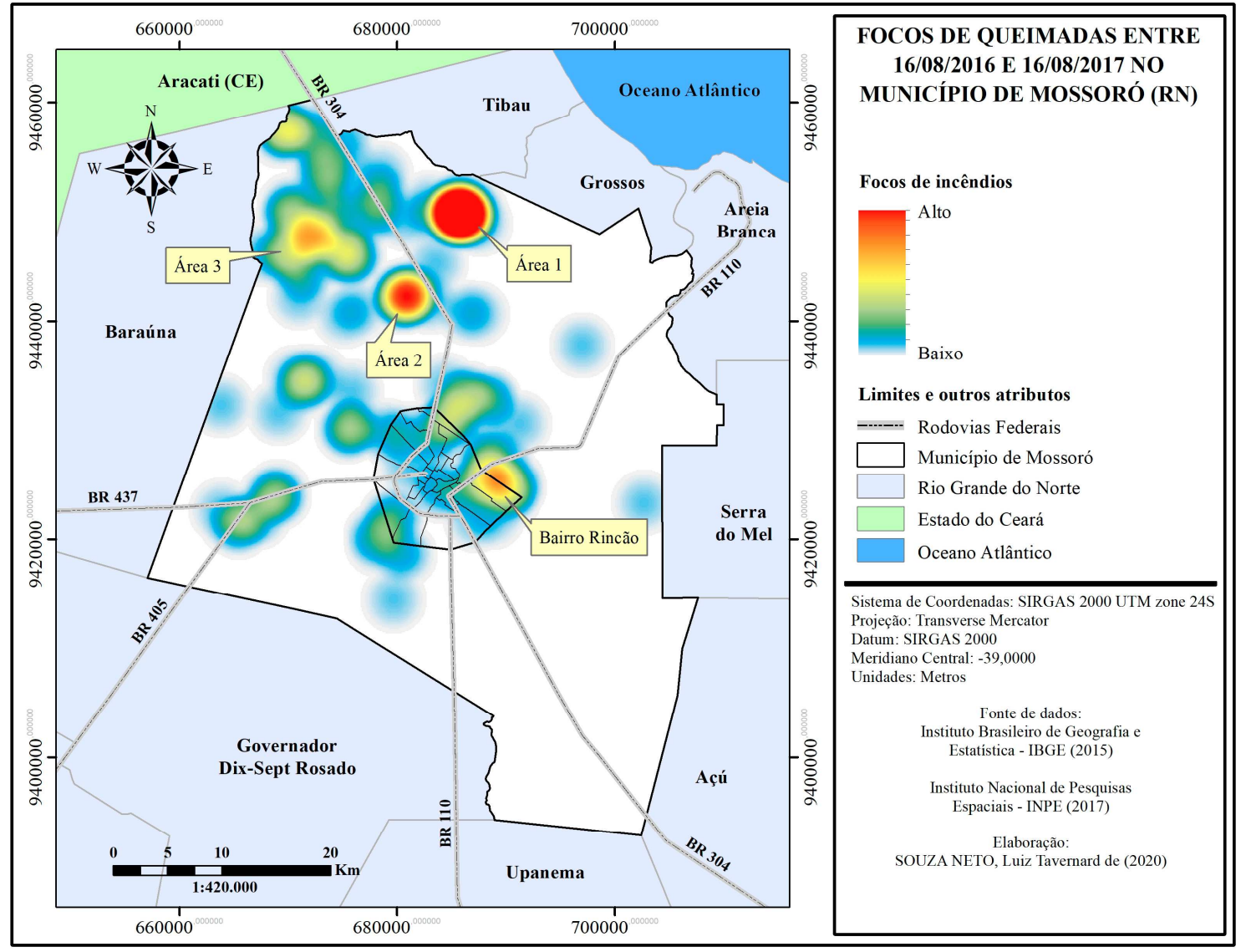

Conforme observado na Figura 7, Mossoró possui quatro áreas críticas de focos de queimadas e incêndios, entre eles: três na zona rural e um na zona urbana. A área 1, está localizada próxima aos municípios de Grossos e Tibau, e se demostra como sendo uma região com atividade agrícola bem recente, onde é observamos que antes da ocorrência dos focos, a área ainda se encontrava com sua vegetação nativa em estado de conservação (Figura 8).

É importante destacar que na área mencionada foram identificados 69 focos de queimadas entre os dias 10 de novembro de 2016 e 10 de dezembro do mesmo ano. Já as imagens dispostas na figura 8, são datadas de 21 de setembro de 2016 (Figura 8A) e 15 de fevereiro de 2017 (Figura 8B).

Conforme observado, a atividade agrícola é o principal vetor das queimadas em Mossoró. Para contornar essa situação, práticas alternativas devem ser tomadas, por exemplo, roça no toco (CARCARA e MOITA NETO, 2012), cobertura morta (OLIVEIRA et al., 2002) 
e plantio direto (CRUZ et al., 2001). Essas técnicas contribuem para uma agricultura sustentável (CAPORAL e COSTABEBER, 2004).

Figura 8 - Dispersão dos focos da área e observação de atividade recente nas coordenadas de referência UTM Zona 24 S 685832 E / 9449963 N (SIRGAS 2000): a) 21/09/2016; b) 15/02/2017.
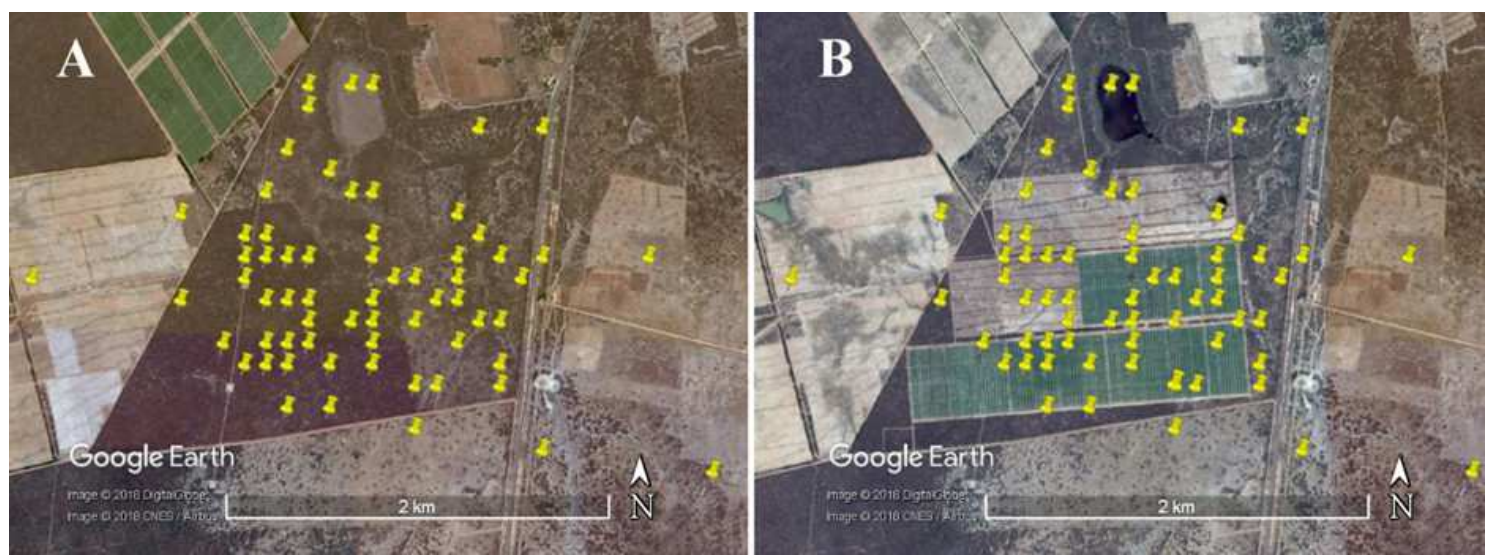

Fonte: Adaptado de Google Earth Pro (2015); IBGE (2017).

Com relação aos focos de incêndio observados no perímetro urbano, mais precisamente no bairro Rincão, identificamos 21 focos de queimadas distribuídos entre os dias 19 de agosto de 2016 a 15 de agosto de 2017. Cabe destacar que em áreas urbanas, as principais ocorrências são advindas de limpeza de terrenos para loteamentos habitacionais e incineração de resíduos sólidos domésticos. Vale ressaltar que a incineração de resíduos sólidos domésticos oferece sérios riscos à saúde humana (GOUVEIA, 2012).

Em ambos os casos, a legislação brasileira é clara quanto a questão do uso do fogo no manejo em áreas urbanas. Com relação ao uso do fogo em aglomerados urbanos, o Decreto Federal 2.661/1998 dispõe em seu Art. $1^{\circ}$, Inciso IV, $\S 3^{\circ}$, que,

Após 9 de julho de 2003, fica proibido o uso do fogo, mesmo sob a forma de queima controlada, para queima de vegetação contida numa faixa de mil metros de aglomerado urbano de qualquer porte, delimitado a partir do seu centro urbanizado, ou de quinhentos metros a partir do seu perímetro urbano, se superior (Redação dada pelo Decreto $\mathrm{n}^{\circ}$ 3.010, de 1999) (BRASIL, 1998a).

Ao confrontar esse dispositivo legal com os dados disponibilizados pelo Programa Queimadas do Instituto Nacional de Pesquisas Espaciais (INPE), compreende-se que os focos de queimadas identificados no bairro Rincão, inflige diretamente o que dispõe Art. $1^{\circ}$, Inciso IV, $\S 3^{\circ}$ do Decreto Federal 2.661/1998 (a). Além disso, ao considerar que as queimadas podem ser decorrentes das ações antrópicas para destinação final de resíduos sólidos ou rejeitos, a Lei 
Federal 12.305/2010, que Institui a Política Nacional de Resíduos Sólidos (BRASIL, 2010), aponta que:

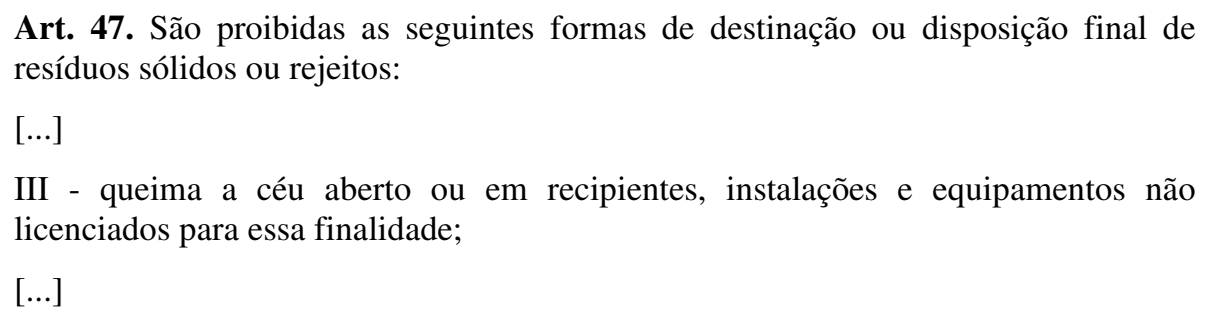

Art. 47. São proibidas as seguintes formas de destinação ou disposição final de resíduos sólidos ou rejeitos:

$[\ldots]$

III - queima a céu aberto ou em recipientes, instalações e equipamentos não licenciados para essa finalidade;

$[\ldots]$

Ainda segundo as tratativas da legislação brasileira, a "Lei de Crimes Ambientais", Lei Federal no 9.605/1998, em seu Artigo 41, é bem clara sobre as penalidades decorrentes do uso indiscriminado do fogo em matas ou florestas,

\section{$[\ldots]$}

Art. 41. Provocar incêndio em mata ou floresta:

Pena - reclusão, de dois a quatro anos, e multa.

Parágrafo único. Se o crime é culposo, a pena é de detenção de seis meses a um ano, e multa.

[...] (BRASIL, 1998b).

\section{CONSIDERAÇÕES FINAIS}

Os resultados obtidos por esta pesquisa demonstraram que o uso de dados dos focos de queimadas do Programa Queimadas do Instituto Nacional de Pesquisas Espaciais (INPE) em associação com o método de dispersão utilizado no mapa de Kernel, se apresentam como uma ferramenta importante que auxilia na identificação e análise da dispersão dos focos de queimadas e incêndios, sobretudo no município de Mossoró (RN).

De tal como, destacam-se as limitações com relação aos produtos gerados pelos sensores, com resolução do pixel variando de $1 \mathrm{~km}$ x $1 \mathrm{~km}$ até $5 \mathrm{~km}$ x $5 \mathrm{~km}$, alguns focos se demonstraram ser pertinentes as observações, nas áreas rurais e urbana. O que pode ser comprovado pelos registos das imagens de satélites do Google Earth Pro e das fotografias no local.

Outro ponto a ser observado é a grande concentração do número de focos em períodos de estiagem. Período este, bem característico do semiárido, onde o município de Mossoró está inserido, o que corrobora com a concepção de que em períodos sem chuvas, o uso da técnica 
de queimada controlada tem ocorrido com mais frequência para limpar áreas para o desenvolvimento de atividades agrícolas. A área mais crítica nos dois períodos analisados, situa-se na porção noroeste do município, nos domínios de vários assentamentos rurais, entre eles, o assentamento Maísa, importante polo agrícola do estado do Rio Grande do Norte.

Com relação aos focos identificados na área urbana, ainda é necessário realizar uma pesquisa mais detalhada, na busca por dados secundários com as instituições de fiscalização para poder confrontar com os dados disponibilizados pelo INPE, e assim trazer mais confiabilidade e interpretações mais precisas para validar as informações produzidas. Contudo, é imperativo destacar a quantidade de focos identificados na área urbana do município, na ordem de 45 ocorrências dispersos por vários bairros.

Por fim, salienta-se a necessidade de investimentos mais especializados em geotecnologias e políticas públicas que possibilitem uma investigação em escalas maiores, que possam adentrar na perspectiva da observação do local, com mais precisão e acurácia.

\section{REFERÊNCIAS}

ANDRADE, A. A. Agricultura e economia espacial em Mossoró/RN: dinâmicas e especificidade regional. In: XI ENCONTRO NACIONAL DA ANPEGE, 2015, 11, Presidente Dutra. Anais... 2015.p. 4419-4430.

ASSOCIAÇÃO CAATINGA. Queimada controlada. Fortaleza: Associação Caatinga. 2011.

BEATO, C.; ASSUNÇÃO, R. Sistemas de informação georreferenciados em segurança. In: BEATO, C. (Org.). Compreendendo e avaliando: projetos de segurança pública. Belo Horizonte: Editora UFMG, 2008. p. 11-62.

BRASIL. Decreto Federal n ${ }^{\circ}$ 2.661, de 8 de julho de 1998 (a). Regulamenta o parágrafo único do art. 27 da Lei $n^{\circ} 4.771 / 1965$ (código florestal), mediante o estabelecimento de normas de precaução relativas ao emprego do fogo em práticas agropastoris e florestais. Diário Oficial da União, Brasília, DF, 8 de julho de 1998.

. Lei Federal n ${ }^{\circ}$ 9.605, de 12 de fevereiro de 1998 (b). Dispõe sobre as sanções penais e administrativas derivadas de condutas e atividades lesivas ao meio ambiente. Diário Oficial da União, Brasília, DF, 13 de fevereiro de 1998.

. Lei Federal no 12.305, de 2 de agosto de 2010. Institui a Política Nacional de Resíduos Sólidos. Diário Oficial da União, Brasília, DF, 2 de agosto de 2010. 
CÂMARA, G.; MONTEIRO, A. M. V. Conceitos Básicos em Ciência da Geoinformacão. In: CÂMARA, G.; MONTEIRO, A. M. V. Introdução à Ciência da Geoinformacão. São José dos Campos: INPE, 2001, p. 1-35.

CAPORAL, F. R.; COSTABEBER, J. A. Agroecologia: alguns conceitos e princípios. Brasília: MDA. 2004.

CARCARA, M. S. M.; MOITA NETO, J. M. Queimadas rurais: necessidade técnica ou questão cultural? In: ROCHA, J.R.S.; BARROS, R.F.M. \& ARAÚJO, J.L.L. (Org.).

Sociobiodiversidade no meio norte brasileiro. (7 ed) Teresina: EDUFPI, 2012. p. 79-100.

CPRM - SERVIÇO GEOLÓGICO DO BRASIL. Projeto cadastro de fontes de abastecimento por água subterrânea: diagnóstico do município de Mossoró, estado do Rio Grande do Norte. Recife: CPRM/PRODEEM, 2005. Disponível em: http://rigeo.cprm.gov.br. Acesso em: 5 jul. 2017.

CRUZ, J. C.; PEREIRA FILHO, I. A.; ALVARENGA, R. C.; SANTANA, D. P. Plantio direto e sustentabilidade do sistema agrícola. Informe Agropecuário, v. 22, p.13-24, 2001. EMPARN - EMPRESA DE PESQUISA AGROPECUÁRIA DO RIO GRANDE DO NORTE. Monitoramento Pluviométrico Anual do Município de Mossoró (2017). Natal: EMPARN, 2017.

FERNANDES, R. C.; CARVALHO, A. L. Espacialização da precipitação pluvial no Município de Piranhas, Alagoas. Ciência e Natura, v. 35, p.295-303, 2014. FLORENZANO, T. G. Sensoriamento Remoto para Geomorfologia. In: FLORENZANO, T. G. (org.). Geomorfologia: conceitos e tecnologias tuais. São Paulo: Oficina de Textos, 2008, p. 31-71.

GONÇALVES, K. S.; CASTRO, H. A.; HACON, S. S. Tendência da mortalidade por doenças respiratórias em idosos e as queimadas no Estado de Rondônia/Brasil: período entre 1998 e 2005. Ciência e Saúde Coletiva, v. 14, p.2083-2090, 2009.

\section{GOOGLE. 2015. GOOGLE EARTH PROTM . Software Versão 7.1.5.1557.}

GOUVEIA, N. Resíduos sólidos urbanos: impactos socioambientais e perspectiva de manejo sustentável com inclusão social. Ciência e Saúde Coletiva, v. 17, p.1503-1510, 2012.

GRANEMANN, D. C.; CARNEIRO, G. L. Monitoramento de focos de incêndio e áreas queimadas com a utilização de imagens de sensoriamento remoto. Revista de Engenharia e Tecnologia, v. 1, p.55-62, 2009.

HIGA, L. T.; SCHLICHTING, A. F.; CATALANI, T. G. T.; GRIGIO, A. M.; GAMARRA, R. M.; PARANHOS FILHO, A. C. Modelos de estabilidade dos solos a erosão. Anuário do Instituto de Geociências - UFRJ, v. 37, p.05-15, 2014. 
IBGE - INSTITUTO BRASILEIRO DE GEOGRAFIA E ESTATÍSTICA. Censo Demográfico de 2010. Rio de Janeiro: IBGE, 2010.

IBGE - INSTITUTO BRASILEIRO DE GEOGRAFIA E ESTATÍSTICA. Produção Agrícola Municipal 2015. Rio de Janeiro: IBGE, 2016. Disponível em: http://cidades.ibge.gov.br/. Acesso em: 12 ago. 2017.

INPE - INSTITUTO NACIONAL DE PESQUISAS ESPACIAIS, 2017. Portal do Monitoramento de Queimadas e Incêndios. Disponível em http://www.inpe.br/queimadas. Acesso em: 10 ago. 2017.

LIU, W. T. H. Aplicações de sensoriamento remoto. Campo Grande: UNIDERP. 2006.

MEIRELLES, M. S. P.; MOREIRA, F. R.; CAMARA, G. Técnicas de inferências espaciais. In: CAMARA NETTO, G.; ALMEIDA, C. M. (Org.). Geomática: Modelos e Aplicações Ambientais. 1. ed. Brasilia: Embrapa Informação Tecnológica, 2007. p. 105-189.

MELO, F. P.; SOUZA, R. M. E.; ROSS, J. L. S. Modelagem de geoformas para mitigação do risco geoambiental em Garanhuns-PE. Acta Geográfica (UFRR), v. 10, 2016. p. 87-105.

MOITA NETO, J.M; CARCARA, M.S.M. Queimadas rurais: necessidade técnica ou questão cultural? In: ROCHA, J.R.S.; BARROS, R.F.M. \& ARAÚJO, J.L.L. (Org.).

Sociobiodiversidade no meio Norte Brasileiro. (7 ed) Teresina: EDUFPI, 2012. p.79-100.

NASCIMENTO, L. F; DE MEDEIROS, A. P. Admissions due to pneumonia and biomass burning: a spatital approach. Jornal de Pediatria, v. 88, p.177-183, 2012.

NOVO, E. M. L. M. Sensoriamento Remoto: Princípios e Aplicações. (3 ed). São Paulo: Blucher. 2008.

OLIVEIRA, F. N. S.; LIMA, A. A. C; AQUINO, A. R. L.; MAIA, S. M. F. Influência da cobertura morta no desenvolvimento de fruteiras tropicais. Fortaleza: Embrapa Agroindústria Tropical. 2002.

OLIVEIRA, U. C.; OLIVEIRA, P. S. Mapas de kernel como subsídio à gestão ambiental: análise dos focos de calor na Bacia Hidrográfica do Rio Acaraú, Ceará, nos anos 2010 a 2015. Espaço Aberto, v. 7, p.87-99, 2017.

PARANHOS FILHO, A. C.; MARCATO JUNIOR, J.; GAMARRA, R. M. Dados espaciais. In: PARANHOS FILHO, A. C.; MIOTO, C. L.; CATALANI, T. G. T.; MARCATO JUNIOR, J. (Org.). Geotecnologias em Aplicações Ambientais. 1. ed. Campo Grande: Editora da UFMS, 2016. p. 205-212.

PRATES, C. J. N.; BARBOSA, R. P.; FOGAÇA, J. J. N. L.; LEMOS, O. L.; DUTRA, F. V.; SILVA, R. M. Análise Multitemporal de Uso e Ocupação do Solo com Enfoque na 
Silvicultura no Município de Cândido Sales, Bahia, nos Anos de 2005 e 2015. Anuário do Instituto de Geociências - UFRJ, v. 40, p.150-155, 2017.

QGIS DEVELOPMENT TEAM. 2018. QGIS Desktop Versão 3.0.3. Open Source Geospatial Foundation.

QUEIROZ, L. P. Leguminosas da Caatinga. Feira de Santana: UEFS. 2009.

RODRIGUES, J.A.; LIBONATI, R.; PERES, L.F. \& SETZER, A. Mapeamento de Áreas Queimadas em Unidades de Conservação da Região Serrana do Rio de Janeiro Utilizando o Satélite Landsat-8 Durante a Seca de 2014. Anuário do Instituto de Geociências - UFRJ, v. 41, p.318-327, 2018.

SANT' ANA, R. M. S.; CARVALHO, S. S.; JESUS, A. B. Espacialização das ocorrências da companhia de polícia de proteção ambiental - COPPA, através do uso de geotecnologias.

Revista Eletrônica: tempo, técnica e território, v. 5, p.62-71, 2014.

VILAR, J. A. P.; SILVA, J. B. S. Detecção de focos de calor no estado da paraíba: um estudo sobre as queimadas. Revista Geográfica Acadêmica, v.10, p.5-16, 2016.

XIMENES, A. C.; ALMEIDA, C. M.; SILVANA, A.; ESCADA, M. I. S.; AGUIAR, A. P. D. Modelagem dinâmica do desmatamento na Amazônia. Boletim de Ciências Geodésicas, v. 14: p.370-390, 2008.

YAMAMOTO, J. K.; LANDIM, P. M. B. Geoestatística: conceitos e aplicações. São Paulo: Oficina de Textos, 2013. 